Saudi Journal of Oral and Dental Research

Abbreviated Key Title: Saudi J Oral Dent Res

ISSN 2518-1300 (Print) |ISSN 2518-1297 (Online)

Scholars Middle East Publishers, Dubai, United Arab Emirates

Journal homepage: https://saudijournals.com

\title{
Bilateral Distomolars in a Sudanese Female: A Case Report
}

Rhma Almomen*

Dental Intern, College of Dentistry, King Saud University Saudi Arabia

DOI: $10.36348 /$ sjodr.2021.v06i01.010 $\quad$ | Received: 01.01.2021 | Accepted: 09.01.2021 | Published: 16.01 .2021

*Corresponding author: Rhma Almomen

\section{Abstract}

Supernumerary teeth are any odontogenic structure that is found in the dental arch in excess number. They are classified based on quantity, location, morphology, and orientation. There is no internationally used numbering system for supernumerary teeth. In this article, the numbering system of the Oklahoma Health Care Authority will be used. 27-yearold medically fit Sudanese female presented to the emergency clinics in the College of Dentistry, King Saud University. After extraoral and intraoral examinations, two distomolars were discovered distal to \#18 and \#28. The prevalence of distomolars is rare. Most of the time they are an incidental finding. The etiology of supernumerary teeth remains unclear. The treatment options for supernumerary teeth vary greatly.

Keywords: Supernumerary teeth, distomolars, teeth numbering system.

Copyright (C) 2021 The Author(s): This is an open-access article distributed under the terms of the Creative Commons Attribution 4.0 International License (CC BY-NC 4.0) which permits unrestricted use, distribution, and reproduction in any medium for non-commercial use provided the original author and source are credited.

\section{INTRODUCTION}

Supernumerary teeth are "any tooth or odontogenic structure that is formed from tooth germ in excess of usual number for any given region of the dental arch [1]. Supernumerary teeth can be classified according to their quantity, location, morphology, and orientation. Single or multiple supernumerary teeth can be found in the dental arch [2]. According to their location, they can be mesiodens (located in the maxillary midline), paramolars (located in the vestibule between 2nd and 3rd molars, distomolars (distal to 3rd molars).

According to their resemblance of normal anatomy of the adjacent teeth. If they have anatomy close to their neighboring teeth they are called supernumerary. While if they have an irregular shape then they're considered rudimentary. Rudimentary teeth are further classified into conical, tuberculate, and molariform types [3]. Supernumerary teeth can also have different positions in the arch. They can be vertical, inverted, or even transverse [4]. Distomolars are most of the time rudimentary teeth that are located distal to the last molar [4].

Supernumerary teeth are more common in the permanent dentition $(1.5 \%-3.5 \%)$ than the deciduous $(0.3-0.8 \%)$ and in the maxilla than the mandible [5]. Males have a double tendency to have supernumerary teeth than females [6]. Distomolars are a rare finding; most of the time is diagnosed only by radiographic means [7].

The etiology of supernumerary teeth is not clear. Many theories have been introduced to explain their development. Some articles have suggested a genetic etiology [8]. The presence of an autosomal dominant gene is responsible for extra teeth in the dentition. But this pattern is believed to be present if the supernumerary teeth are associated with a syndrome such as cleidocranial dysplasia [9]. Another theory suggested a hypertrophic tooth germ might be the cause of supernumerary teeth [10]. The unifying theory suggests the multifactorial model, meaning that environmental and genetic predisposition together might be the true etiology of supernumerary teeth [11].

The numbering system for supernumerary teeth is not universally standardized. The system in this article is the one used in the Oklahoma Health Care Authority (Fig-1), where the supernumerary dentition is given the numbers from 51 to 82 . Starting systematically from the most distal tooth in the right maxilla and ending with the last tooth in the lower right quadrant [12]. For permanent dentition, the FDI numerical system is used [13].

The treatment options for supernumerary teeth are variant. Many options have been suggested. The most widely used treatment is extraction. The timing of the extraction is also an important factor, for extracting 
Rhma Almomen; Saudi J Oral Dent Res, Jan 2021; 6(1): 50-53

the supernumerary teeth might affect the adjacent developing dentition [14]. Another option is to reposition the supernumerary teeth [15], especially if they are not rudimentary. Supernumerary teeth can be kept under observation as long as they do not possess any risk to the adjacent teeth or have any accompanying form of pathology [15].

$$
\begin{array}{l|l}
515253.5455565758 & 5960616263646566 \\
\hline 8281807978777675 & 7473727170696867
\end{array}
$$

Fig-1: The numbering system of Oklahoma Health Care Authority for supernumerary dentition

\section{CASE REPORT}

27-year-old Sudanese female presented to the emergency clinics in the college of dentistry, King Saud University to restore \#26 and \#27. Her medical history revealed an appendectomy procedure done 8 years ago in Sudan and no current medical issues. After extraoral and intraoral examinations, two distomolars were discovered distal to \#18 and \#28 (Fig-2,3 and 4). Both teeth are clinically free of caries and with good periodontal condition. A panoramic radiograph and a bitewing for \#27 and \#26 were requested. Both radiographs revealed that both teeth are not associated with any pathological condition. Regarding their form, Tooth no.51 has conical crown anatomy. Racial pigmentation was also noticed in the buccal gingiva (Fig-5). Tooth no.66 resembles a deciduous molar, particularly \#75 with its small 5 cusps (Fig-6). Both distomolars are rotated. The patient never knew she had those teeth in her mouth.

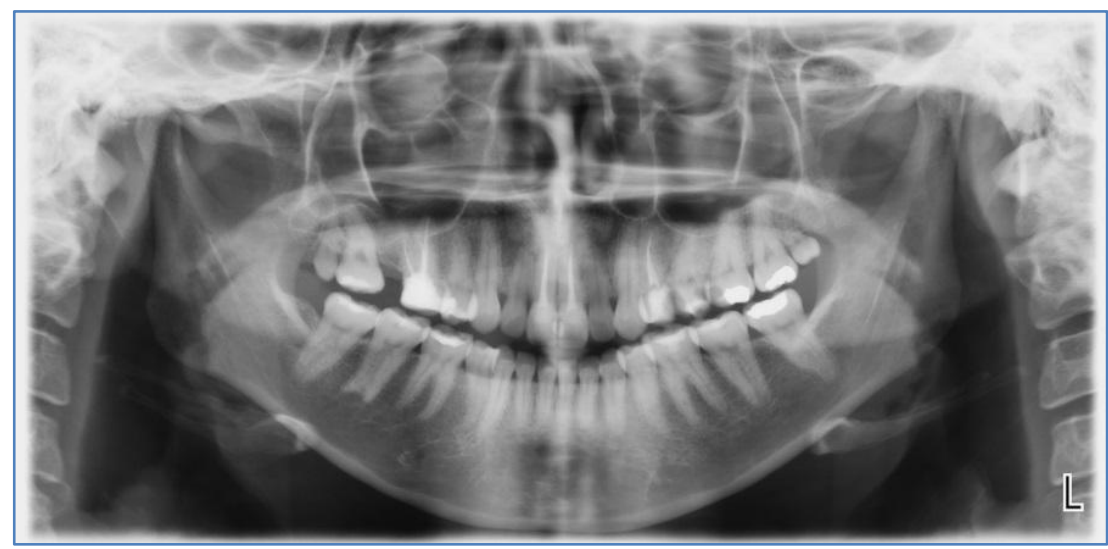

Fig-2: A Panoramic radiograph showing two distomolars distal to \#18 and \#28

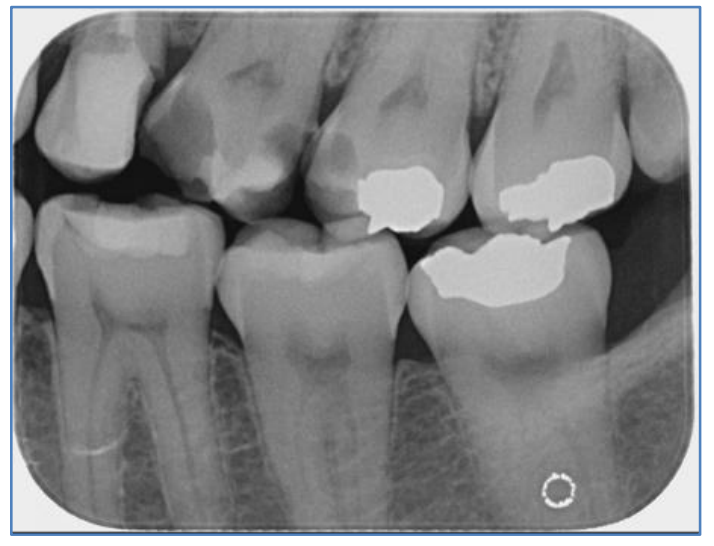

Fig-3: Left bitewing radiograph. Notice tooth no.66 distal to \#28.

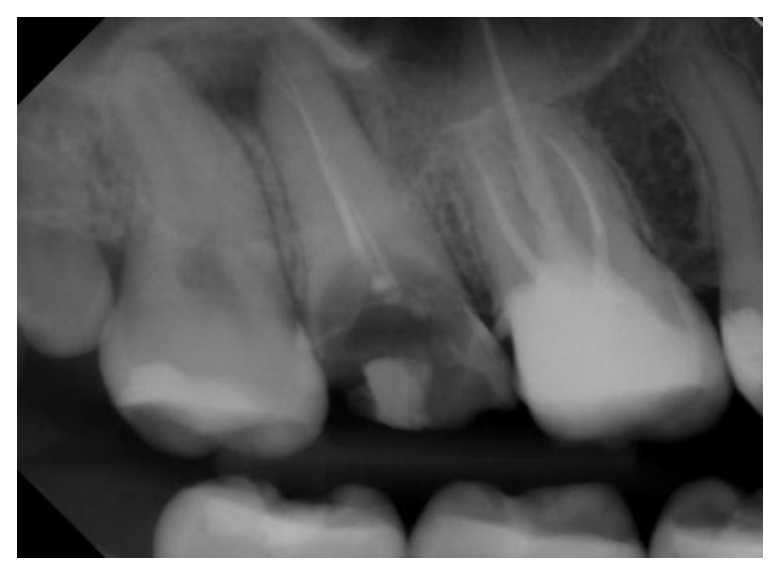

Fig-4: Right periapical radiograph. Notice tooth no. 51distal to \#18. 
Rhma Almomen; Saudi J Oral Dent Res, Jan 2021; 6(1): 50-53

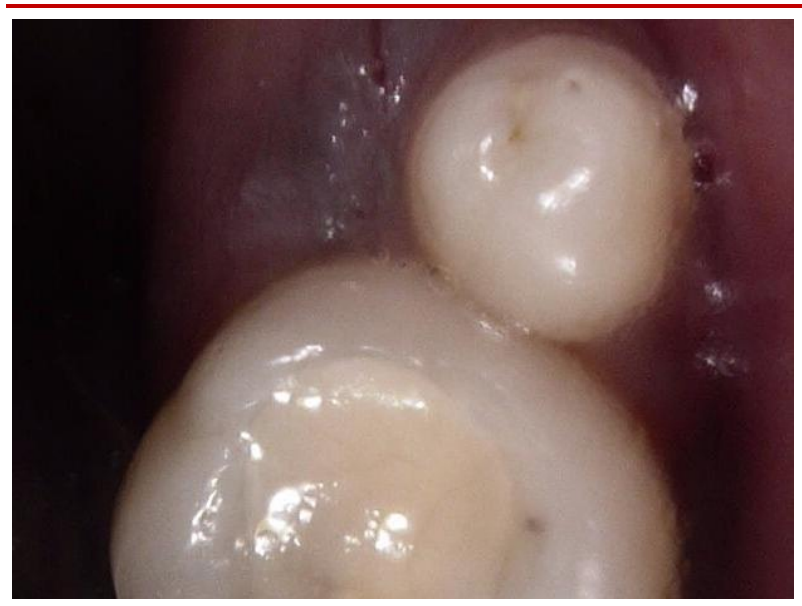

Fig-5: Intraoral photos of tooth no.51. Note the conical shape of the crown. Racial pigmentation present in the buccal gingiva

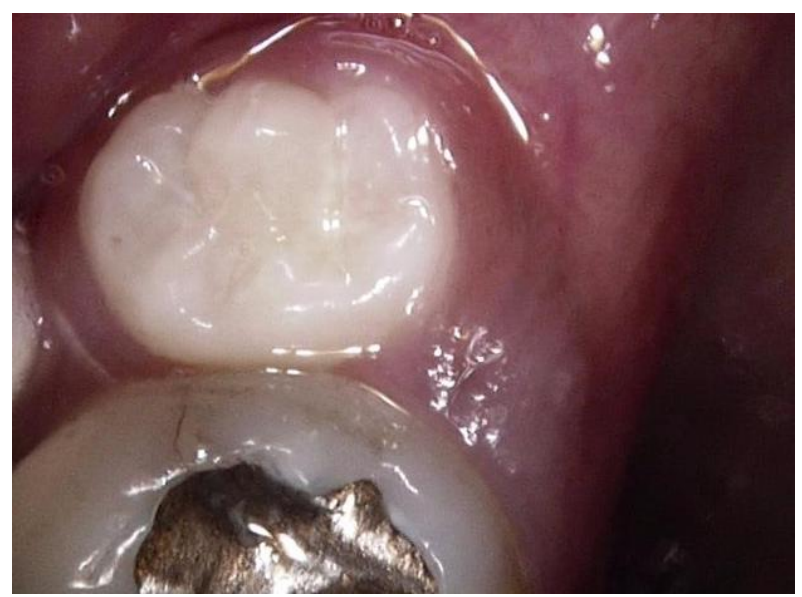

Fig-6: Intraoral photos of tooth no.66. Its occlusal table is very similar to \#75

\section{DISCUSSION}

Additional teeth in the jaw exceeding the 20tooth deciduous dentition or the 32-tooth permanent one are known as supernumerary teeth [16].

There are multiple criteria to classify supernumerary teeth: quantity, location, morphology, and orientation. Distomolars are supernumerary teeth located distal to the last permanent molar [5]. Although in this case, they're erupting normally, most of the time distomolars are discovered by chance during the radiographic examination [7].

The prevalence of supernumerary teeth in the permanent dentition is ranged from $1.5 \%$ to $3.5 \%$. Which is higher than the deciduous dentition $(0.3 \%$ $0.8 \%$ ). They are more common in males than females in a proportion of $2: 1[5]$. No data in the literature was found regarding the prevalence of supernumerary teeth in the Sudanese population.

The etiology of supernumerary teeth is not clear. The unifying theory suggests the multifactorial model, meaning that environmental and genetic predisposition together might be acceptable for the case presented as she also showed another anomaly; taurodontism [11].

Still, there is no universal method to number supernumerary teeth. Standardized systems should be considered around the world for easier communication and management.

The treatment options for supernumerary teeth are variant. Many options have been suggested. The most widely proposed treatment is extraction. The timing of the extraction is also an important factor, for extracting the supernumerary teeth might affect the adjacent developing dentition [14]. Another option is to reposition the supernumerary teeth [15], especially if they are not rudimentary. Supernumerary teeth can be kept under observation as long as they do not possess any risk to the adjacent teeth or have any accompanying form of pathology [15].

In this case, the decision was made to keep teeth no.51 and no.66 under frequent observation. Since they're free of caries, with good gingival condition, and have no sign of associated pathology. The fact that the patient didn't notice their presence indicates that they're not interfering with normal oral function.

\section{CONCLUSION}

Supernumerary teeth can have many shapes and forms and can be located in different sites in the dental arch. Distomolars are rare to find. While there is no published prevalence of supernumerary teeth in Sudan, this is the first documented case for supernumerary teeth in a Sudanese woman. Careful intraoral and radiographic examinations are necessary to detect any supernumerary tooth as other teeth anomalies. Treatment options might differ depending on the current situation of these teeth when noticed.

\section{REFERENCES}

1. Orner, R. S. M., Anthonappa, R. P., \& King, N. M. (2010). Determination of the optimum time for surgical removal of unerupted anterior supernumerary teeth. Pediatric Dentistry.

2. Garvey, M. T., Barry, H. J., \& Blake, M. (1999). Supernumerary teeth--an overview of classification, diagnosis and management. Journal (Canadian Dental Association).

3. Parul, J., Rahul, Kaul, S. S. (2017). Rare Molariform Supernumerary Teeth: Why is They Bilateral? Abstract. Indian Journal of Dental Research, 29(2), 212-216. https://doi.org/10.4103/ijdr.IJDR

4. Shah, A., Gill, D. S., Tredwin, C., \& Naini, F. B. (2008). Diagnosis and management of supernumerary teeth. Dental Update. https://doi.org/10.12968/denu.2008.35.8.510 
Rhma Almomen; Saudi J Oral Dent Res, Jan 2021; 6(1): 50-53

5. Ata-Ali, F., Ata-Ali, J., Peñarrocha-Oltra, D., \& Peñarrocha-Diago, M. (2014). Prevalence, etiology, diagnosis, treatment and complications of supernumerary teeth. Journal of Clinical and Experimental https://doi.org/10.4317/jced.51499

Dentistry.

6. Giancotti, A., Grazzini, F., De Dominicis, F., Romanini, G., \& Arcuri, C. (2002). Multidisciplinary evaluation and clinical management of mesiodens. The Journal of Clinical Pediatric Dentistry.

7. Schofield, J. (1973). Multiple symmetrical supernumerary molar teeth. British Dental Journal, 135(10), 455-456. doi: 10.1038/sj.bdj.4803100

8. Prasada Rao, P. V. V., \& Chidzonga, M. M. (2001). Supernumerary teeth: Literature review. Central African Journal of Medicine, 47(1), 22-26. https://doi.org/10.26444/jpccr/119037

9. Lubinsky, M., \& Kantaputra, P. N. (2016). Syndromes with supernumerary teeth. American Journal of Medical Genetics, Part A. https://doi.org/10.1002/ajmg.a.37763

10. SAARENMAA L. (1951). The origin of supernumerary teeth. Acta odontologica Scandinavica, 9(3-4), 293-303. https://doi.org/10.3109/00016355109012791

11. Brook, A. H. (1984). A unifying aetiological explanation for anomalies of human tooth number and size. Archives of Oral Biology. https://doi.org/10.1016/0003-9969(84)90163-8

12. Authority, O., Rules, P., Rules, P., Specialties, I., \& System, T. (2021). Tooth numbering system. Retrieved 6 January 2021, from https://oklahoma.gov/ohca/policies-andrules/xpolicy/medical-providers-fee-forservice/individual-providers-andspecialties/dentists/tooth-numbering-system.html

13. Smith, H. (2021). Fédération Dentaire Internationale (FDI) notation | Radiology Reference Article | Radiopaedia.org. Retrieved 6 January 2021, from https://radiopaedia.org/articles/federation-dentaireinternationale-fdi-notation

14. Orner, R. S. M., Anthonappa, R. P., \& King, N. M. (2010). Determination of the optimum time for surgical removal of unerupted anterior supernumerary teeth. Pediatric Dentistry.

15. Parolia, A., Kundabala, M., Dahal, M., Mohan, M., \& Thomas, M. S. (2011). Management of supernumerary teeth. Journal of Conservative Dentistry. https://doi.org/10.4103/0972-0707.85791

16. Leco Berrocal, M. I., Martín Morales, J. F., \& Martínez González, J. M. (2007). An observational study of the frequency of supernumerary teeth in a population of 2000 patients. Medicina Oral, Patologia Oral y Cirugia Bucal. 